\title{
THE RENAL CLEARANCE OF ALKALI-STABLE INULIN
}

\author{
By MACKENZIE WALSER, DOUGLAS G. DAVIDSON, AND JACK ORLOFF
}

\author{
(From the Laboratory of Kidney and Electrolyte Metabolism, National Heart Institute, Na- \\ tional Institutes of Health, Public Health Service, Department of Health, Educa- \\ tion and Welfare, Bethesda, Md.)
}

(Submitted for publication May 31, 1955; accepted June 15, 1955)

Commercial inulin available at present is not a homogeneous product (1). It consists of two major fractions the proportions of which vary: (a) a portion of relatively large molecular weight resistant to heating in alkali; and (b) a portion of smaller molecular weight susceptible to destruction with alkali. In addition, most samples contain a small percentage of fructose, which also yields color in the analytical methods for inulin unless removed by treatment with yeast or hot alkali.

Two recent reports $(2,3)$ indicate that the clearance of the alkali-stable and alkali-labile fractions of inulin may not be equal. Since some commercial preparations of inulin (such as the one used in this study) may contain as much as 50 per cent of the alkali-labile material, considerable errors in estimation of glomerular filtration rate would occur if a difference in clearance of the two fractions exists.

The present report indicates that the clearance of the two fractions is identical, within the limits of error of analysis, in confirmation of the preliminary report by Cotlove (1).

\section{METHODS}

Subjects. The subjects were patients of the National Heart Institute at the Clinical Center. One was a normal volunteer. The others had renal or endocrine diseases. In most cases studies were performed in the fasting state. The comparisons were made during clearance determinations performed for other purposes.

Procedure. Before each clearance determination, the ampoules of inulin to be used were mixed together and a portion withdrawn for analysis. ${ }^{1}$ A priming injection and a sustaining infusion of inulin were administered intravenously. The plasma level of the alkali-stable fraction was approximately $13 \mathrm{mg}$. per cent. After a 30 to 40-minute equilibration period, 3 to 8 urine collection periods were obtained, each of 20 to 40 minutes' duration.

1 Inulin was obtained from the Warner-Chilcott Laboratories. According to the manufacturers it contains less than 0.5 per cent fructose.
Blood for analysis was obtained in a syringe containing heparin at the midpoint of each period.

Analytical methods. Alkali-stable inulin in plasma and urine was determined by a modification of published methods (4-7) as follows: protein-free plasma filtrates were prepared according to Somogyi (8) by adding $7 \mathrm{ml}$. of water, $1 \mathrm{ml}$. of $\mathrm{ZnSO}_{4}$ reagent, ${ }^{2}$ and $1 \mathrm{ml}$. $0.75 \mathrm{~N}$ $\mathrm{NaOH}$ (dropwise and with constant mixing) to $1 \mathrm{ml}$. of plasma. After 20 minutes, during which the flasks were shaken occasionally, the solutions were centrifuged and the supernatant decanted. ${ }^{3}$ Duplicate $2 \mathrm{ml}$. aliquots of supernatant, appropriately diluted urine and standards were pipetted into $20 \times 150 \mathrm{~mm}$. tubes. Five-tenths $\mathrm{ml}$. of $4 \mathrm{~N} \mathrm{NaOH}$ was added from a $1 \mathrm{ml}$. Krogh-Keys syringe-pipette. The tubes were covered with marbles and placed in a $100^{\circ} \mathrm{C}$. bath for 20 minutes. ${ }^{4}$ After cooling, $6.25 \mathrm{ml}$. of diphenylamine reagent ${ }^{5}$ were added from a $10 \mathrm{ml}$. Krogh-Keys syringe-pipette. Mixing was unnecessary if the reagent was injected vigorously. The marbles were replaced and the tubes were reheated in the $100^{\circ}$ bath for 30 minutes, ${ }^{6}$ cooled, and read at 620 $\mathrm{m} \mu$ in a Coleman Jr. spectrophotometer.

"Total" inulin was determined according to the method of Harrison (6) as modified by Kennedy and Kleh (7). One ml. samples of plasma or diluted urine were treated with yeast; plasma protein was precipitated with $\mathrm{ZnSO}_{4}{ }^{2}$ and $\mathrm{NaOH}$, diphenylamine reagent ${ }^{5}$ was added and the tubes were heated at $100^{\circ} \mathrm{C}$. for 30 minutes, cooled, and read at $620 \mathrm{~m} \mu$ in the spectrophotometer. A small percentage of yeast-labile material $(<5$ per cent of the total) was found in some of the inulin samples. No correction was made for this. Standards for both methods consisted of 3 dilutions of a sample of the infused inulin. The recovery of inulin added to plasma at the same 3 concentrations was determined. These concentrations correspond to 5,10 , and $15 \mathrm{mg}$. per cent

2 One hundred $\mathrm{gm}$. $\mathrm{ZnSO}_{4} \cdot 7 \mathrm{H}_{2} \mathrm{O}$ and $40 \mathrm{ml} .6 .25 \mathrm{~N}$ $\mathrm{H}_{2} \mathrm{SO}_{4}$ diluted to $1,000 \mathrm{ml}$.

3 The use of filter paper was found both to absorb inulin and add to the reagent blank, leading to spurious results.

4 Since completion of these studies, it has been found that an 8 to $10 \mathrm{~min}$. period of heating with alkali is adequate.

5 Fourteen gm. diphenylamine (Mathesen), $600 \mathrm{ml}$. glacial acetic acid, $360 \mathrm{ml}$. conc. $\mathrm{HCl}$.

6 A constant temperature bath filled with oil and mechanically stirred provided better temperature regulation than a boiling water bath. 
TABLE I

The ratio of the clearance of alkali-stable inulin to total inulin *

\begin{tabular}{|c|c|c|c|c|c|c|}
\hline Subject & Age & Diagnosis & $\begin{array}{c}\text { Average } \\
\text { GFR } \\
\text { mb./min. }\end{array}$ & $\begin{array}{c}\text { Number of } \\
\text { periods }\end{array}$ & $\begin{array}{l}\text { Mean } \\
\text { ratio }\end{array}$ & $\underset{\text { inulin }}{\text { \% Stable }}$ \\
\hline $\begin{array}{l}\text { Ree } \\
\text { Hen } \\
\text { Haz } \\
\text { Gib } \\
\text { Gib } \\
\text { Gar } \\
\text { Hol } \\
\text { Win } \\
\text { Win } \\
\text { Son } \\
\text { Son } \\
\text { Dot } \\
\text { Dot } \\
\text { Dot } \\
\text { Dot } \\
\text { Dot } \\
\text { Dot }\end{array}$ & $\begin{array}{r}22 \\
42 \\
29 \\
9 \\
9 \\
33 \\
39 \\
50 \\
50 \\
29 \\
29 \\
9 \\
9 \\
9 \\
9 \\
9 \\
9\end{array}$ & $\begin{array}{l}\text { Normal } \\
\text { Renal artery thrombosis } \\
\text { Chronic glomerulonephritis } \\
\text { Addison's disease } \\
\text { Addison's disease } \\
\text { Nephrotic syndrome } \\
\text { Nephrotic syndrome } \\
\text { Nephrotic syndrome } \\
\text { Nephrotic syndrome } \\
\text { Nephrotic syndrome } \\
\text { Nephrotic syndrome } \\
\text { Nephrogenic diabetes insipidus } \\
\text { Nephrogenic diabetes insipidus } \\
\text { Nephrogenic diabetes insipidus } \\
\text { Nephrogenic diabetes insipidus } \\
\text { Nephrogenic diabetes insipidus } \\
\text { Nephrogenic diabetes insipidus }\end{array}$ & $\begin{array}{r}94 \\
32 \\
132 \\
54 \\
50 \\
82 \\
115 \\
72 \\
119 \\
25 \\
47 \\
57 \\
45 \\
35 \\
46 \\
55 \\
42\end{array}$ & $\begin{array}{l}8 \\
2 \\
3 \\
4 \\
3 \\
3 \\
3 \\
3 \\
4 \\
4 \\
5 \\
7 \\
7 \\
7 \\
6 \\
2 \\
8\end{array}$ & $\begin{array}{l}0.99 \\
1.00 \\
1.07 \\
1.06 \\
1.02 \\
0.97 \\
1.04 \\
1.04 \\
1.00 \dagger \\
0.99 \\
1.01 \ddagger \\
0.96 \\
1.05 \\
0.96 \\
0.99 \\
0.99 \\
0.95\end{array}$ & $\begin{array}{l}\mathbf{4 8} \\
\mathbf{5 2} \\
\mathbf{5 2} \\
\mathbf{5 2} \\
\mathbf{5 3} \\
\mathbf{5 0} \\
\mathbf{5 0} \\
\mathbf{5 1} \\
\mathbf{5 6} \\
\mathbf{5 1} \\
\mathbf{5 5} \\
\mathbf{5 8} \\
\mathbf{5 3} \\
\mathbf{5 1} \\
\mathbf{5 1} \\
\mathbf{5 3} \\
\mathbf{4 8}\end{array}$ \\
\hline & & & & 79 & & \\
\hline
\end{tabular}

* Mean of all observed periods, considering the repeated analyses in "Win" and "Son" as additional periods = $1.003 \pm 0.011$ (S.E.).

t Calculated from mean of three independent analyses by each method.

$\ddagger$ Calculated from mean of five independent analyses by each method.

alkali-stable inulin in plasma in the alkali method and 10,20 , and $30 \mathrm{mg}$. per cent inulin in plasma in the yeast method. The fraction of the infused inulin resistant to alkali digestion was also determined in each instance. Alkali did not interfere with the color development.

In the later experiments the results were expressed in terms of a standard inulin solution consisting of pure alkali-stable inulin, prepared as follows:

Preparation of alkali-stable inulin. Fifty $\mathrm{gm}$. of "Difco" inulin (approximately 85 per cent alkali-stable) were dissolved in $50 \mathrm{ml}$. of $1 \mathrm{~N} \mathrm{NaOH}$ at $100^{\circ} \mathrm{C}$. and heated for 2 hours. The solution was cooled under the tap and then placed in a cold room for several hours. One-hundred $\mathrm{ml}$. of distilled water were added to the fudge-like mass and the precipitate suspended by prolonged stirring. Another $100 \mathrm{ml}$. of distilled water were added and the solution centrifuged for 30 minutes. The supernatant was decanted and the precipitate washed repeatedly in this manner, using progressively smaller volumes of water, until no further whitening occurred. Inulin was reprecipitated by heating at $100^{\circ} \mathrm{C}$. and adding just enough water for solution, filtering, cooling rapidly, adding (with shaking) 2 volumes of acetone and filtering by suction. Twenty grams of white material were obtained. Inulin so prepared was not destroyed by yeast.

Analytical results. The relation between optical density and concentration is linear in both the yeast and the alkali methods, throughout the useful range of the colorimeter. The recovery of inulin added to plasma was $100.0 \pm 2.3^{7}$ per cent in 67 samples analyzed by the alkali method and $100.7 \pm 2.0$ per cent in 62 samples analyzed by the yeast method. The plasma inuloid blank

\footnotetext{
7 Standard deviation.
}

averaged $0.9 \mathrm{mg}$. per cent in the yeast method and 0.4 mg. per cent in the alkali method.

Additional observations on the alkali method. Using the procedure described, the range of 30 to 70 per cent transmission in the colorimeter corresponds to a range of 6 to $16 \mathrm{mg}$. per cent alkali-stable inulin in plasma. Analysis of a solution containing $500 \mathrm{mg}$. per cent glucose resulted in color equivalent to $0.3 \mathrm{mg}$. per cent alkali-stable inulin. ${ }^{8}$ Autoöxidation of inulin was complete as shown by the fact that neither prolongation of the heating period, substitution of $7 \mathrm{~N}$ for $4 \mathrm{~N}$ alkali, nor continuous aeration of the tubes during heating with alkali altered the results.

\section{RESULTS}

Nine subjects were studied on 17 occasions with varying numbers of periods in each study, as shown in Table I. In addition, repeated analyses were performed on the samples from two of the studies. The original data from two representative experiments are shown in Table II together with the ratios of the clearance of alkali-stable (Ca) to "total" inulin as determined after yeasting (Cy). The ratios obtained from repeated analyses of the samples from two experiments are shown in Table III.

8 This ratio of inulin sensitivity to glucose sensitivity of about $1600: 1$ is 5 to 10 times greater than the ratio observed by Little (4). 
TABLE II

\begin{tabular}{|c|c|c|c|c|c|c|c|}
\hline Subject & $\begin{array}{c}\mathrm{Ca} \\
\text { ml./ } \\
\text { min. }\end{array}$ & $\begin{array}{l}\text { Cy } \\
\text { ml./ } \\
m i n .\end{array}$ & $\mathrm{Ca} / \mathrm{Cy}$ & Subject & $\begin{array}{c}\mathrm{Ca} \\
\text { ml./ } \\
\text { min. }\end{array}$ & $\underset{\text { min./ }}{\text { Cy }}$ & $\mathrm{Ca} / \mathrm{Cy}$ \\
\hline 'Ree"' & $\begin{array}{l}98.2 \\
98.2 \\
98.8 \\
94.6 \\
94.1 \\
93.3 \\
94.9 \\
88.3\end{array}$ & $\begin{array}{r}100.0 \\
96.2 \\
97.8 \\
95.7 \\
98.4 \\
99.7 \\
97.5 \\
87.2\end{array}$ & $\begin{array}{l}0.98 \\
1.02 \\
1.01 \\
0.99 \\
0.96 \\
0.94 \\
0.97 \\
1.01\end{array}$ & "Dot" & $\begin{array}{l}40.3 \\
47.0 \\
40.6 \\
36.6 \\
42.7 \\
43.0 \\
38.5 \\
35.4\end{array}$ & $\begin{array}{l}42.6 \\
51.9 \\
42.4 \\
37.8 \\
43.9 \\
43.3 \\
40.2 \\
38.7\end{array}$ & $\begin{array}{l}0.95 \\
0.91 \\
0.96 \\
0.97 \\
0.97 \\
0.99 \\
0.96 \\
0.92\end{array}$ \\
\hline
\end{tabular}

The mean of all the observed ratios of alkalistable inulin clearance to "total" inulin clearance is 1.003 , with a standard error of 0.011 .

Several components of error can be discerned in these data. The standard deviation of the observed ratios obtained within each study is approximately 0.04 . Variability of similar magnitude is found between the ratios from repeated analyses of the samples from a single study (Table III). The variability from subject to subject and from study to study within a single subject ("Dot") is only slightly greater. Considering the 17 studies in all, the standard deviation of a single ratio is 0.05 . The variance of the mean was calculated as a suitable combination of the variance from study to study and the variance within a single study. ${ }^{9}$ We may conclude that

9 Note on Computation of the Variance of the Mean.

Computation of the variance of the mean was complicated by the fact that different numbers of periods were used in different studies and that the individuals had different numbers of studies. Thus, to assess the variability of the mean it was assumed that a given ratio was subject to a variance $\sigma^{2}$, attributable to study-to-study variation and also to a variance $\sigma_{\theta}^{2}$, attributable to technical error and period-to-period variability. This then implies that the mean for a given study has a variance $\sigma^{2}+\frac{\sigma_{0}^{2}}{n_{a}}$, where $n_{a}$ is the number of periods in the study. From this point of view, the mean as computed (a simple average) is equivalent to $\sum_{i=1}^{17} \frac{n_{i} x_{i}}{n}$ where $n_{i}$ is the number of periods in the " $i$ "th study, $\bar{x}_{i}$ is the average ratio for the "i"th study and $n=\sum_{i=1}^{17} n_{i}$. From the above one can show that the variance of $\Sigma \frac{n_{i} \bar{x}_{i}}{n}$ is given by $\sigma^{2} \frac{\sum_{i=1}^{17} n_{i}^{2}}{n^{2}}+\frac{\sigma_{0}^{2}}{n}$. The component $\sigma_{0}^{2}$ was estimated by the variance within studies averaged over all studies. To estimate $\sigma^{2}$ the sum the average value of the ratio is between 0.983 and 1.023 at the 95 per cent level of confidence.

Since the inulin used was approximately one half alkali-stable and one half alkali-labile it follows that the clearance of alkali-stable inulin is on the average equal to that of alkali-labile inulin within approximately 4 per cent, at the 95 per cent level of confidence.

In view of the equality of the clearances of the two major fractions of inulin, it is of little importance whether the inulin used for measurement of filtration rate contains a large or small proportion of alkali-stable material. However, the analysis of inulin by means of the diphenylamine reaction after alkali treatment has several advantages over other methods: (a) The plasma inuloid blank is low; (b) the method is almost completely insensitive to glucose ; and (c) low concentrations of inulin may be determined accurately.

Since alkali-labile inulin is destroyed in this analytical method, it is advantageous to employ inulin containing as much alkali-stable material

TABLE III

Ratios of alkali-stable to total inulin clearance determined from repeated analyses of the samples from two experiments

\begin{tabular}{lcccccc}
\hline & & \multicolumn{5}{c}{ Day of analysis } \\
\cline { 3 - 7 } Subject & Period & 1 & 2 & 3 & 4 & 5 \\
\hline \multirow{3}{*}{ "Son" } & 1 & 1.05 & 1.08 & 1.01 & 1.06 & 1.00 \\
& 2 & 1.06 & 1.09 & 1.14 & 1.01 & 1.05 \\
& 3 & 1.01 & 1.04 & 0.94 & 0.95 & 0.98 \\
& 4 & 0.96 & 0.98 & 1.01 & 0.95 & 1.05 \\
& 5 & 1.04 & 1.01 & 0.96 & 0.98 & 1.03 \\
\hline \multirow{2}{*}{ "Win" } & 1 & 1.10 & 0.97 & 1.00 & & \\
& 2 & 1.00 & 1.00 & 0.98 & & \\
& 3 & 1.00 & 0.91 & 1.00 & & \\
& 4 & 1.04 & 0.99 & 1.03 & & \\
\hline
\end{tabular}

of squares of deviations, $\sum_{i=1}^{17} n_{i}\left(\bar{x}_{i}-\bar{x}\right)^{2}$, was first computed. Here $\bar{x}$ is the grand mean and other symbols are as previously defined. One can show that this sum of squares estimates $\left(n-\frac{\Sigma n_{i}^{2}}{n}\right) \sigma^{2}+16 \sigma_{0}^{2}$. Consequently, this latter expression with our estimated value of $\sigma_{0}^{2}$ substituted was equated to the sum of squares. This equation was then solved for $\sigma^{2}$. The variance of $\overline{\mathbf{x}}$ was estimated using the values so obtained for $\sigma^{2}$ and $\sigma_{0}^{2}$.

It should be remarked that taking the individual as a unit, it was found that the variance among individuals was of order comparable to the variance among studies. A variance of the mean computed on this basis was also comparable to the estimate obtained using studies as a unit. 
as possible. The method of preparation described above is simpler than that described by Weil (9) and permits larger yields of pure alkali-stable material. However, inulin so prepared has only been used in animals in this laboratory. The present data do not establish that inulin purified after alkali treatment has the same clearance as the alkali-stable fraction of inulin prepared without alkali treatment.

\section{SUM MARY}

Improved methods are presented for the determination of alkali-stable inulin in plasma and urine and for the preparation of alkali-stable inulin. The renal clearance of the fraction of commercial inulin not destroyed by alkali is equal to the renal clearance of the fraction of inulin destroyed, within analytical error.

\section{ACKNOWLEDGMENTS}

We are greatly indebted to Dr. Max Halperin for the statistical analysis and to Agnes Scott Preston for technical aid.

\section{REFERENCES}

1. Cotlove, E., Heterogeneity of inulin: chemical, physical and physiologic aspects. Federation Proc., 1954, 13, 30.

2. Handelsman, M. B., and Drabkin, J., Use of anthrone reagent to estimate inulin in the presence of glucose. Proc. Soc. Exper. Biol. \& Med., 1954, 86, 356.

3. Swanson, R. E., Renal excretion of commercial and alkali-stable inulin. Federation Proc., 1955, 14, 149.

4. Little, J. M., A modified diphenylamine procedure for the determination of inulin. J. Biol. Chem., 1949, 180, 747.

5. Cotlove, E., Mechanism and extent of distribution of inulin and sucrose in chloride space of tissues. Am. J. Physiol., 1954, 176, 396.

6. Harrison, H. E., A modification of the diphenylamine method for determination of inulin. Proc. Soc. Exper. Biol. \& Med., 1942, 49, 111.

7. Kennedy, T. J., Jr., and Kleh, J., The relationship between the clearance and the plasma concentration of inulin in normal man. J. Clin. Invest., 1953, 32, 90.

8. Somogyi, M., A method for the preparation of blood filtrates for the determination of sugar. J. Biol. Chem., 1930, 86, 655.

9. Weil, W. B., Preparation of a stable form of inulin for tissue analysis. Proc. Soc. Exper. Biol. \& Med., 1952, 80, 103. 